\title{
Electrical and mechanical responses in the platysma and in the adductor pollicis muscle: in patients with myasthenia gravis
}

\author{
C. KRARUP
}

From the Laboratory of Clinical Neurophysiology, Rigshospital, and the Institute of Neurophysiology, University of Copenhagen, Denmark

SUMMARY Electrical and mechanical muscular responses to single and repetitive stimuli were recorded in 24 patients with myasthenia gravis. Findings in the platysma were compared with those in $\mathrm{m}$. adductor pollicis (ADP). In the platysma, but not in the ADP, electrical and mechanical responses to single stimuli were often lower than normal, and could be normalised after tetanus and by edrophonium. The decrement of electrical and mechanical responses to repetitive stimuli was two to three times greater in the platysma than in the ADP; post-tetanic facilitation of the action potential was four times greater. The staircase phenomenon was abnormal in the platysma in patients with moderate and severe myasthenia, and also in the ADP in some patients without decrement in the action potential. Edrophonium was more effective in alleviating decrement in the platysma than in the ADP. In the platysma, block of neuromuscular transmission could account for most abnormalities. The finding in some patients of an abnormal staircase after correction for block of fibres indicates a lesion in excitation-contraction coupling. In six patients only the platysma showed abnormalities, in 10 patients abnormalities were more pronounced in the platysma than in the ADP, and in three patients more pronounced in the ADP than in the platysma; in five patients the platysma and the ADP were equally affected.

The purpose of this study of patients with myasthenia gravis was to compare the diagnostic yield obtained from recording of the electrical and mechanical responses in a proximal (platysma) and in a distal ( $\mathrm{m}$. adductor pollicis) muscle.

\section{Method}

The recording of electrical and mechanical responses in the platysma has been described (Krarup, 1977). Electrical and mechanical responses were also recorded in $\mathrm{m}$. adductor pollicis (ADP), using the method of Slomić et al. (1968). Findings were compared with those in normal subjects (platysma: Krarup, 1977; ADP: Slomić et al., 1968). The 95\% confidence limits in controls are given in Table 1. The significance of differences between subjects and patients and between patients in the platysma and the ADP were evaluated by the $t$-test.

Accepted 18 October 1976
The temperature on the skin over the platysma $\left(36^{\circ} \mathrm{C}\right)$ was slightly higher than on the skin over the ADP $\left(33^{\circ} \mathrm{C}\right)$, but could not be the reason for the two to three times greater decrement in the platysma than in the ADP (Borenstein and Desmedt, 1974, 1975).

The programme of stimulation has been described (Krarup, 1977). In addition, the effect of edrophonium chloride (Tensilon) was examined on trains of stimuli at $3 \mathrm{~s}^{-1}$. Edrophonium, $10 \mathrm{mg}$, was given intravenously, at first $2 \mathrm{mg}$ and 45 seconds later $8 \mathrm{mg}$. Trains of stimuli were delivered at half minute intervals for up to two minutes, at one minute intervals for up to 10 minutes, and often for up to 25 minutes after the injection.

PATIENTS WITH MYASTHENIA GRAVIS

Twenty-four patients with clinical evidence of myasthenia gravis were examined. Thirteen were females and 11 were males; 11 were $22-38$ years old and 13 were $43-73$ years old. Fifteen had moderate or severe (type IIa-IV, Osserman and Genkins, 1971), 
Table 1 Ninety-five per cent confidence limits of normal subjects*

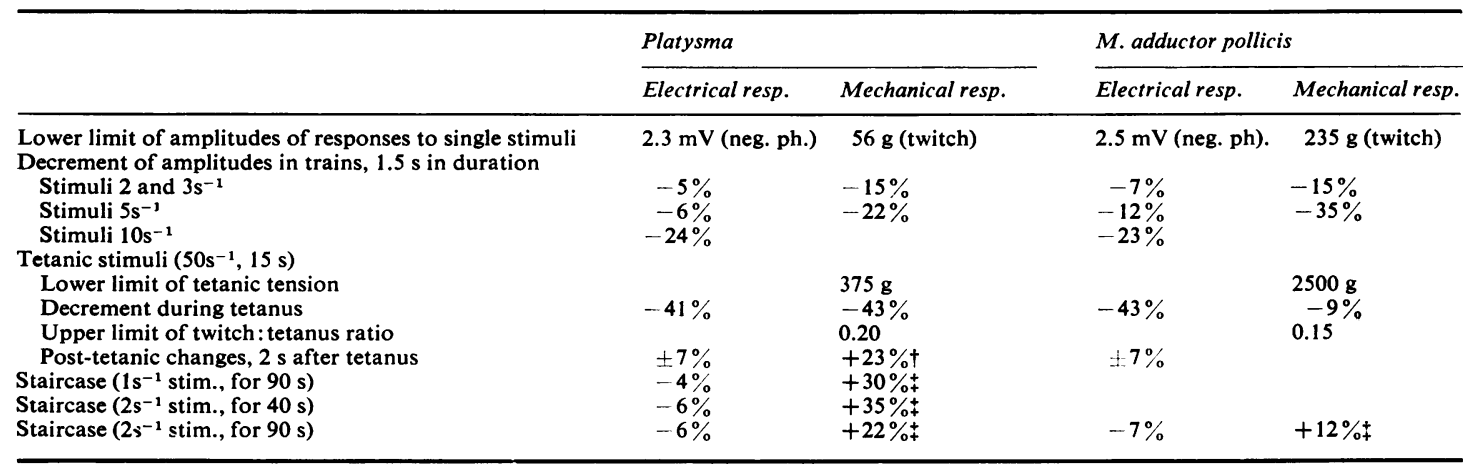

* Data in the ADP are taken from Slomić et al. (1968), and in the platysma from 34 normal subjects (Krarup, 1977).

†Lower post-tetanic potentiation of twitch tension in normal subjects.

¥Lower potentiation of twitch tension during staircase in normal subjects.

eight had mild (mild type IIa or I) clinical involvement, and one was in complete remission. The disease had lasted less than half a year in six, less than two years in eight, and more than two years in 10 patients. Five patients were examined after thymectomy (two with moderate and three with mild myasthenia gravis).

Anticholinesterase medication was discontinued in 14 patients more than 12 hours and in four patients more than four hours before the study. Six patients were not in treatment.

\section{ASSOCIATED DISEASES}

Seven patients had other diseases as well. One had polyathritis, one cancer of the rectum, one systemic lupus erythematosus, and one patient had epilepsy (Osserman and Genkins, 1971; Simpson, 1974). Three patients had evidence of myopathy on EMG of a proximal muscle. One of these had a normal muscle biopsy (m. triceps brachii), one had type A fibre atrophy and lymphorrhages (m. biceps brachii), and one had fibre necrosis and groups of atrophic fibres suggesting neurogenic changes ( $\mathrm{m}$. biceps brachii).

\section{Results}

\section{MODERATE AND SEVERE MYASTHENIA GRAVIS}

\section{Responses to a single stimuli}

In seven of 15 patients the amplitude of the action potential, and also the twitch tension in six, was lower than normal in the platysma, whereas both were normal in the ADP (Fig. 1, Table 2). This is at variance with Johns et al. (1956), Lambert et al. (1961), Slomić et al. (1968), and Desmedt (1973) who found a decreased action potential amplitude and twitch tension in an intrinsic muscle of the hand in severely affected patients. In the platysma the con- traction time was prolonged in six of 15 patients and the half-relaxation time in 10 patients, whereas in the ADP the time course of the twitch was normal (Table 2) except in one patient, who had a $40 \%$ prolonged contraction time.

Responses to trains of stimuli $\left(2-10 s^{-1}\right.$ for $\left.1.5 s\right)$ In the platysma the decrements in the action potential and in the twitch tension were twice those in the ADPO $(\mathrm{P}<0.01)$, and different from normal in both ( $P<0.001$, Figs. 2 and 3). The decrement was invariably present in the platysma but was absent in two patients in the ADP.

\section{Responses to tetanic stimuli}

In the platysma, nine of 14 patients had a decrement in the action potential, whereas only one patient had decrement in the ADP (Figs. 2 and 3). Stimuli at 10, 20 , and 50 per second often elicited an early transient decrement in the action potential. A decrement in the mechanical response occurred in four patients in the platysma and in one in the ADP. Tetanic tension $\left(\mathrm{P}_{0}\right)$ was diminished in eight of 14 patients in the platysma, but in only one in the ADP (Fig. 1, Table 2). The twitch:tetanus ratio $\left(P / P_{0}\right)$ and the rate of relative force development $\left(P / P_{0} / C T\right)$ were increased in nine patients in the platysma and in two in the ADP (Table 2).

\section{MILD MYASTHENIA GRAVIS}

Responses to single stimuli

In three of nine patients in the platysma the amplitude of the action potential, and in two the twitch tension were lower than normal; both the action potential amplitude and the twitch tension were normal in the ADP (Fig. 1, Table 2). The contraction time was normal in both muscles. 


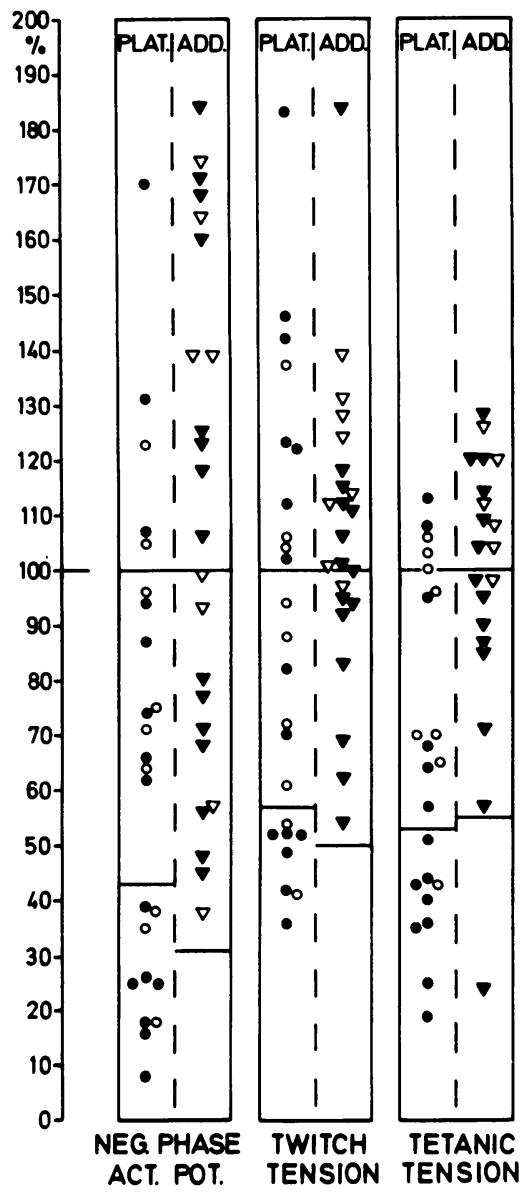

Fig. 1 Amplitude of the action potential, the twitch tension, and tetanic tension in the platysma $(0, \bullet)$ and in the $A D P(\nabla, \nabla)$ in patients with moderate or severe (solid symbols) and with mild myasthenia gravis (open symbols), in per cent of the average in normal subjects (equal 100\%). The horizontal lines at 30-60\% indicate the lower $95 \%$ confidence limits.

\section{Responses to trains of stimuli}

In the platysma five of nine patients had a decrement in the electrical and mechanical response to trains of stimuli at $3 \mathrm{~s}^{-1}$, whereas only one patient had a decrement in the ADP (Fig. 2).

\section{Responses to tetanic stimuli}

With one exception (in the platysma) the tetanic tension was normal in both muscles. There was no decrement at $50 \mathrm{~s}^{-1}$ and the twitch: tetanus ratio was normal (Fig. 2, Table 2).
Post-tetanic changes

MODERATE AND SEVERE MYASTHENIA GRAVIS

An increase in the amplitude of the action potential after tetanus (post-tetanic facilitation of neuromuscular transmission, PTF), occurred more often (Table 3) and was four times greater in the platysma than in the ADP $(+35 \pm 11 \%$ as compared with $+8 \pm 3 \%$, mean \pm m.e., $P<0.05$, Figs. 3 and 4). Pretetanic levels were attained within 10 seconds after tetanus in both muscles, thus earlier than the 20-30 seconds duration of PTF found by Desmedt (1966). Post-tetanic facilitation was followed by a slight transient decrease $(-5 \%, \mathrm{P}<0.05)$ within the first minute after tetanus (Fig. 4).

The twitch tension increased in the platysma less than normal $(+52 \pm 11 \%$, mean \pm m.e., $\mathrm{P}<0.05$, Fig. 4), whereas it was normal in the ADP. The increase was due both to PTF of neuromuscular transmission and to PTP of twitch tension. In the platysma the increased twitch tension decreased steeply within the first 10 seconds and then more slowly. In the ADP the posttetanic twitch decreased more rapidly than normal, but did not show the large difference in the initial and later slope seen in the platysma (Fig. 4).

Post-tetanic exhaustion, present in the platysma and in the ADP in two-thirds of the patients (Table 3), appeared as a $10 \%$ increase in the decrement of $3 \mathrm{~s}^{-1}$ trains with a maximum two to four minutes after tetanus; it had disappeared after six minutes.

\section{MILD MYASTHENIA GRAVIS}

In the platysma PTF was absent and in one-third of the patients even the action potential was diminished, whereas PTF was present in one-third of the ADP (Table 3). The slight transient decrease in the action potential amplitude $(-4 \%, \mathrm{P}<0.05$, Fig. 4) within the first minute was present only in the platysma. PTP was normal in both muscles, though it decreased more rapidly than normal in the ADP (Fig. 4). The pretetanic decrement in $3 \mathrm{~s}^{-1}$ trains was borderline in four patients in the platysma and in one in the ADP, but was abnormal after tetanus (post-tetanic exhaustion, Table 3).

\section{Staircase phenomenon}

MODERATE AND SEVERE MYASTHENIA GRAVIS

A decrement in the amplitude of the action potential was present in all 14 patients in the platysma and in 11 of 15 patients in the ADP (Fig. 5); the decrement was three times greater at $2 \mathrm{~s}^{-1}$ for 90 seconds in the platysma than in the ADP $(-54 \pm 6 \%$ compared with $-18 \pm 5 \%$, mean \pm m.e., $P<0.001$, Figs. 3 and 6 ). The decrement in the action potential was 1.5 times greater at a stimulus frequency of $2 \mathrm{~s}^{-1}$ than at 
Table 2 Responses to single and tetanic stimuli

\begin{tabular}{|c|c|c|c|c|c|c|c|c|c|c|c|c|}
\hline & \multicolumn{6}{|c|}{ Platysma } & \multicolumn{6}{|c|}{ M. adductor pollicis } \\
\hline & \multicolumn{3}{|c|}{$\begin{array}{l}\text { Moder. and sev. } \\
\text { myasth. grav. }\end{array}$} & \multicolumn{3}{|c|}{$\begin{array}{l}\text { Mild } \\
\text { myasth. grav. }\end{array}$} & \multicolumn{3}{|c|}{$\begin{array}{l}\text { Moder. and sev. } \\
\text { myasth. grav. }\end{array}$} & \multicolumn{3}{|c|}{$\begin{array}{l}\text { Mild } \\
\text { myasth. grav. }\end{array}$} \\
\hline & $n$ & mean & $S D \%$ & $n$ & mean & $S D \%$ & $n$ & mean & $S D \%$ & $n$ & mean & $S D \%$ \\
\hline \multicolumn{13}{|l|}{ Electrical response } \\
\hline Amplitude of negative phase (mV) & 13 & $3.7 \dagger$ & 67 & 9 & $3.7 \dagger$ & 50 & 15 & 8.5 & 45 & 8 & 9.0 & 43 \\
\hline Amplitude of peak-to-peak (mV) & 15 & $4.1+$ & 76 & 9 & 5.5 & 51 & 15 & 14.3 & 38 & 8 & 14.8 & 45 \\
\hline Latency of muscle act. pot. (ms) & 15 & 3.1 & 19 & 9 & 3.1 & 23 & 15 & 2.6 & 11 & 8 & 2.8 & 13 \\
\hline \multicolumn{13}{|l|}{ Mechanical response } \\
\hline Twitch tension ( $P$ in $g)$ & 15 & 90 & 50 & 9 & 83 & 36 & 15 & 480 & 39 & 8 & 530 & 18 \\
\hline Contraction time (CT in ms) & 15 & $59 \S$ & 11 & 9 & 50 & 11 & 14 & 70 & 15 & 8 & 68 & 17 \\
\hline Relaxation time (ms) & 15 & $53 * 8$ & 19 & 9 & $46 * \ddagger$ & 13 & 14 & $87^{*}$ & 16 & 8 & $77^{*}$ & 14 \\
\hline Latency of the twitch (ms) & 14 & 8.0 & 12 & 9 & 7.3 & 12 & 14 & 7.4 & 9 & 7 & 6.9 & 16 \\
\hline Rate of relat. force develop. $\left(\mathrm{P} / \mathrm{P}_{0} / \mathrm{CT}\right)$ & 14 & $4.5 \S$ & 38 & 8 & 3.0 & 21 & 14 & 2.0 & 74 & 6 & 1.5 & 34 \\
\hline Twitch: tetanus ratio $\left(P / P_{0}\right)$ & 14 & $0.26 \S$ & 41 & 8 & 0.15 & 23 & 14 & $0.13 \dagger$ & 62 & 6 & 0.10 & 11 \\
\hline Tetanic tension $\left(\mathbf{P}_{0}\right.$ in $\left.\mathbf{g}\right)$ & 14 & $403 \S$ & 52 & 8 & 578 & 28 & 14 & 4260 & 30 & 6 & 5020 & 10 \\
\hline
\end{tabular}

$n$ : number of patients.

SD \%: the SD from subject to subject in per cent of the mean.

* Half relaxation time measured in the platysma, three-fourth relaxation time in the ADP.

Statistical differences $(\dagger P<0.05, \ddagger P<0.01, \S \mathrm{P}<0.001)$ between patients with myasthenia gravis and control subjects in the platysma (Krarup, 1977) and in the ADP (Slomić et al., 1968).

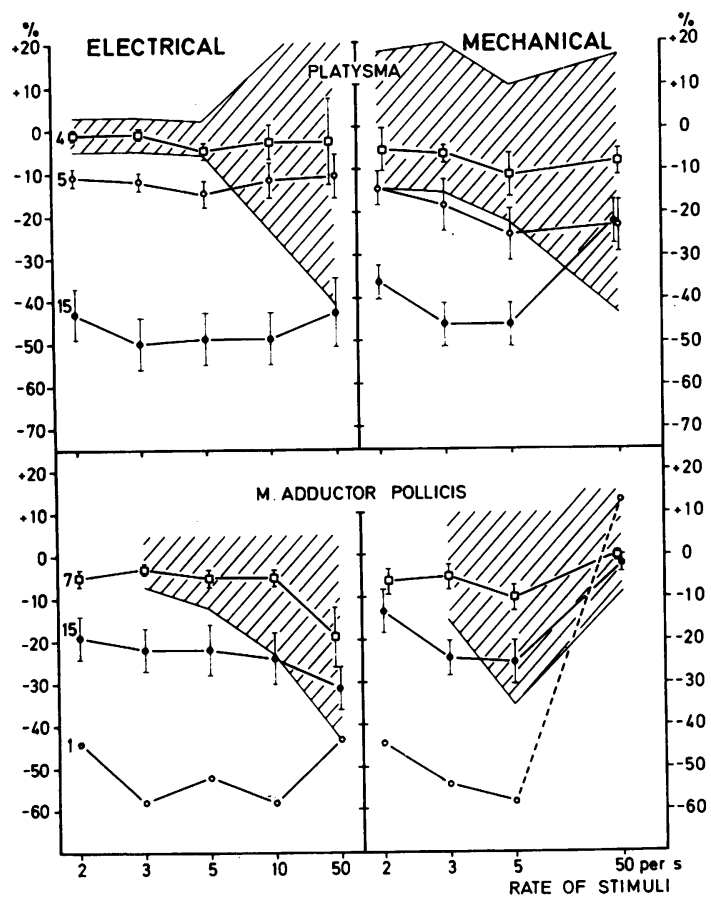

Fig. 2 Percentage change in the amplitude of the action potentials (left) and the mechanical responses (right) in the platysma (above) and in the ADP (below) at different frequencies of stimulation (trains of stimuli 1.5 seconds in duration). Patients with moderate or severe (solid symbols) and with mild myasthenia gravis (open symbols, $O$ with decrement during $3 s^{-1}$ trains, $\square$ without decrement during $3 s^{-1}$ trains)s The figures to the left of the curves indicate the number of patients. The hatched area denotes the $95 \%$ confidence limits of normal.
$1 \mathrm{~s}^{-1}(\mathrm{P}<0.05$, Fig. 6). In both muscles the decrement was most marked within the first five seconds of the train. The steep decrement was followed by a furthe slow decrement which persisted throughout the $9 \oplus$ seconds' duration of the train (Bergmans et al., 1972) The staircase of the twitch tension was either negative or abnormally low ( $P<0.001$, Figs. 5 and 6$)$ in 13 of 14 patients in the platysma and in 12 of 15 patients in the ADP.

Poststaircase responses in platysma

Half a minute after the train the amplitude of the action potential in the platysma was $10 \%$ lower than before the staircase $(\mathrm{P}<0.001$, Fig. 7). Normal amplitudes were reached six to 10 minutes after the train. Paradoxically, the potentiation of twitch tension after the staircase was $10 \%$ larger after the $1 \mathrm{~s}^{-1}$ than after the $2 \mathrm{~s}^{-1}$ staircase, though it was two to five times smaller than normal after both $(\mathrm{P}<0.01$ and $<0.001$, Fig. 7).

\section{MILD MYASTHENIA GRAVIS}

A decrement in the action potential was present in three of nine patients in the platysma and in the ADP, and when present it was only slight, except in one patient (Fig. 5).

In the platysma the staircase was normal $(\mathrm{P}<0.1)$, except in one patient; in the ADP it was lower than normal $(P<0.05)$ in two patients (Figs. 5 and 6).

\section{Poststaircase responses in the platysma}

The action potential, twitch potentiation, and the time for twitch tension to return to resting levels were normal in the platysma (Fig. 7). 

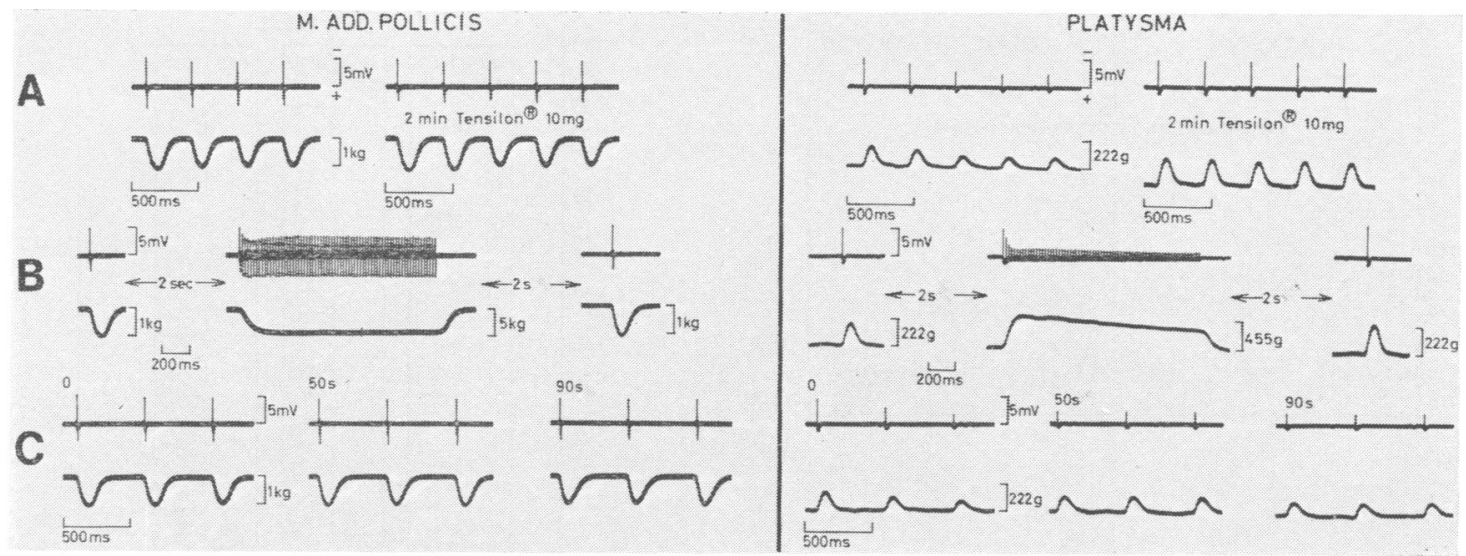

Fig. 3 Greater decrement in the electrical (upper traces) and the mechanical responses (lower traces) in the platysma than in the ADP in a patient with myasthenia gravis. A: $3 s^{-1}$ trains (1.5 seconds in duration) before and after edrophonium, $10 \mathrm{mg}$. B: tetanic stimuli (50 stimuli per second for 1.5 seconds) and single stimuli delivered hefore and after tetanus to show the greater post-tetanic facilitation of the action potential in the platysma than in the ADP.C: $2 s^{-1}$ trains for 90 seconds; a staircase was absent in the platysma and in the ADP.

Table 3 Changes in amplitude of action potential and twitch tension after a 50 per second tetanus

\begin{tabular}{|c|c|c|c|c|c|c|c|c|}
\hline & \multicolumn{4}{|l|}{ Platysma } & \multicolumn{4}{|c|}{ M. adductor pollicis } \\
\hline & \multicolumn{2}{|c|}{$\begin{array}{l}\text { Action potential } \\
\text { (negative phase) }\end{array}$} & \multirow{2}{*}{$\begin{array}{l}\begin{array}{l}\text { Twitch } \\
\text { tension }\end{array} \\
\text { Increase }\end{array}$} & \multirow{2}{*}{$\begin{array}{l}3 s^{-1} \text { train } \\
1.5 s \text { dur. } \\
\text { Exhaustion }\end{array}$} & \multicolumn{2}{|c|}{$\begin{array}{l}\text { Action potential } \\
\text { (negative phase) }\end{array}$} & \multirow{2}{*}{$\begin{array}{l}\begin{array}{l}\text { Twitch } \\
\text { tension }\end{array} \\
\text { Increase }\end{array}$} & \multirow{2}{*}{$\begin{array}{l}3 s^{-1} \text { train } \\
1.5 s \text { dur. } \\
\text { Exhaustion }\end{array}$} \\
\hline & Facilitation & Depression & & & Facilitation & Depression & & \\
\hline $\begin{array}{l}\text { Normal subjects } \\
\text { Moderate and severe }\end{array}$ & $0 / 22$ & $1 / 22$ & $26 / 27$ & $0 / 22$ & $0 / 22$ & $0 / 11$ & $13 / 14$ & $2 / 17$ \\
\hline $\begin{array}{l}\text { myasthenia gravis } \\
\text { Mild myasthenia gravis }\end{array}$ & $\begin{array}{c}10 / 14 \\
0 / 8\end{array}$ & $\begin{array}{l}1 / 14 \\
3 / 8\end{array}$ & $\begin{array}{c}12 / 14 \\
8 / 9\end{array}$ & $\begin{array}{l}9 / 12 \\
5 / 6\end{array}$ & $\begin{array}{l}6 / 14 \\
2 / 6\end{array}$ & $\begin{array}{l}1 / 14 \\
0 / 6\end{array}$ & $\begin{array}{c}10 / 13 \\
5 / 6\end{array}$ & $\begin{array}{l}8 / 14 \\
1 / 4\end{array}$ \\
\hline
\end{tabular}

Data from normal subjects in the platysma are taken from Krarup (1977) and in the ADP from Slomić et al. (1968).

The denominator denotes the number of normal subjects and patients examined, and the numerator the number with positive findings.

\section{Edrophonium chloride}

In the platysma the decrement after edrophonium in the action potential and in twitch tension was diminished (Fig. 3) in all patients with moderate and severe and in all but one of the patients with mild involvement. In the ADP, edrophonium caused a decrease in decrement in two-thirds of the patients with moderate and severe, and in half of the patients with mild involvement. The effect of edrophonium was maximal half a minute after the injection; it was still present after 10 minutes, but had disappeared after $15-20$ minutes.

\section{Discussion}

This study was designed to compare abnormalities of electrical and mechanical responses in myasthenia gravis in a proximal (platysma) and in a distal (ADP) muscle. The clinical finding (Simpson, 1960; Osserman and Genkins, 1971) was confirmed that proximal muscles are often affected earlier and more severely than distal muscles.

In the platysma the action potential amplitude and twitch tension were often lower than normal. This could be due to block or to loss of muscle fibres. Histological evidence of 'neurogenic atrophy' in myasthenic muscle has been reported by Fenichel and Shy (1963), Brody and Engel (1964), Fenichel (1966), Brownell et al. (1972), and Oosterhuis and Bethlem (1973) and was seen in one patient in the brachial biceps muscle in this study. Others have attributed a shortened duration of voluntarily (Oosterhuis et al., 1972) or electrically evoked (Ballantyne and Hansen, 1974 a,b) motor unit potentials to degeneration of distal nerve branches or to block of end plates. The latter could be reversed by edrophonium. My finding that the action potential increased after tetanus and after edrophonium also indicates block of some muscle fibres in the rested muscle. The contraction time in the platysma was prolonged, consistent with the type II (fast) fibre 


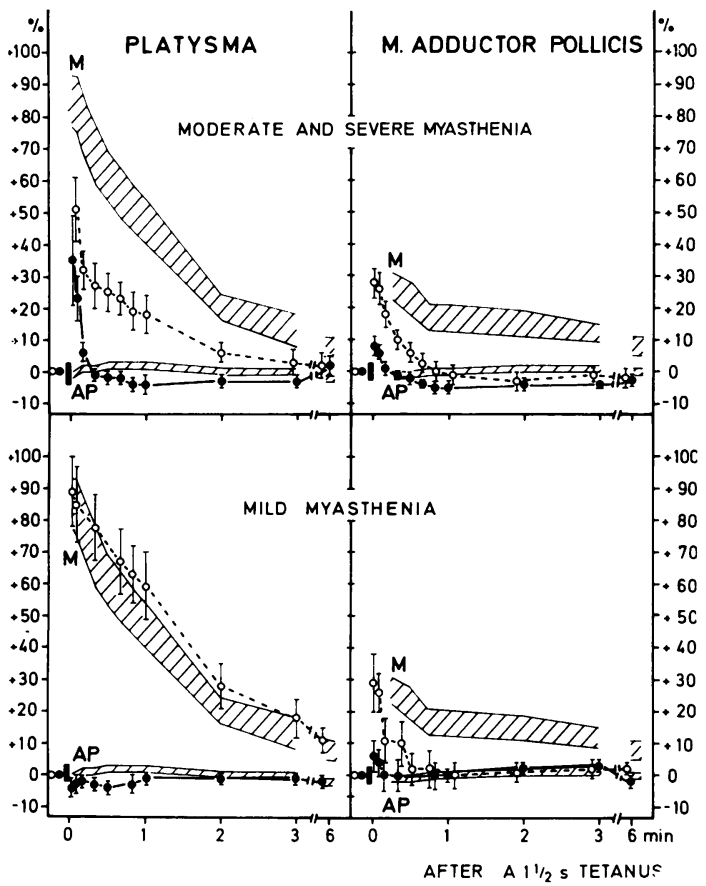

Fig. 4 Post-tetanic facilitation of the action potential $(A P, \odot)$ and post-tetanic potentiation of twitch tension $(M, O)$ in the platysma (left) and in the ADP (right) as a function of time after tetanus (50 stimuli per second for 1.5 seconds) in per cent of pretetanic responses in patients with myasthenia gravis. The hatched area denotes findings in normal subjects \pm mean error. The vertical bars denote the mean error.

atrophy reported in myasthenic muscle by Engel and McFarlin (1966), Brooke and Engel (1969), and Oosterhuis and Bethlem (1973). One patient in my material showed type A fibre atrophy in the brachial biceps muscle.

Slomić et al. (1968) assumed impairment of the excitation-contraction coupling in addition to neuromuscular block because the staircase was diminished or absent in two-thirds of their patients even after correction for block. Desmedt et al. (1973) contested this interpretation, because a relative potentiation of the twitch was present during the staircase of curarised normal muscle (Reinhold et al., 1970), and was similar to that in myasthenia gravis (Desmedt et al., 1973).

Potentiation was less than normal in the platysma and in the ADP in $30-35 \%$ of the patients after correction for block of fibres. In the ADP of three patients (without signs of myopathy) this was the case even when there was no decrement in the action potential. The abnormal staircase would be consistent

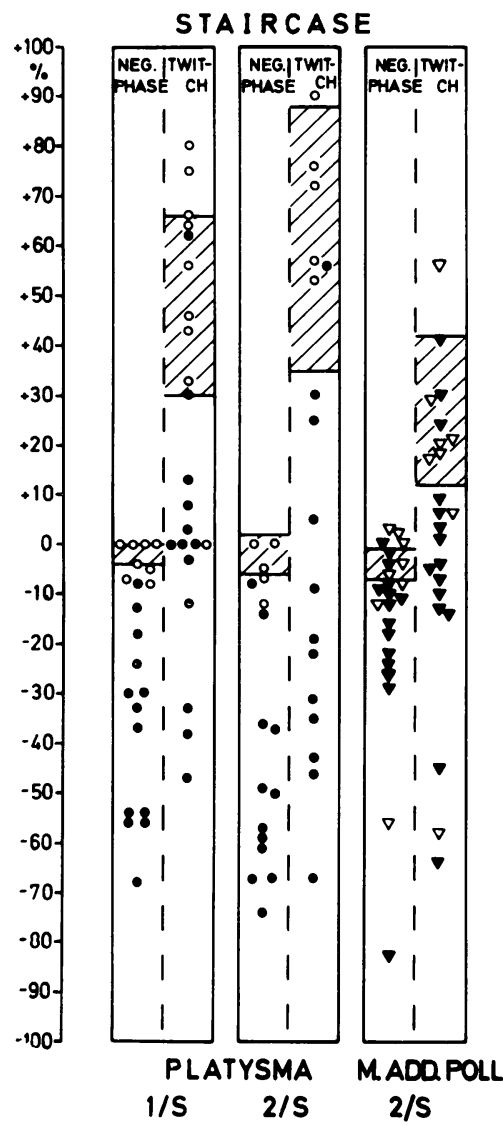

Fig. 5 Changes in the negative phase of the action potential and twitch tension during the staircase in per cent of the first response in the platysma ( 1 and $2 s^{-1}$ for 90 seconds $)$ and in the ADP $\left(2 s^{-1}\right.$ for 90 seconds $)$ in patients with moderate or severe (solid symbols) and mild myasthenia gravis (open symbols). The hatched areas denote the lower $95 \%$ range of normal.

with the structural disorganisation in the sarcoplasmic reticulum and T-tubules, described in muscles of patients with myasthenia gravis by Bergman et al. (1971).

Desmedt et al. (1973), on the other hand, assumed excitation-contraction coupling to be normal in myasthenia gravis because the twitch was potentiated after a train of stimuli that produced a staircase in normal subjects. In the platysma, potentiation after the staircase was much less than normal, the diminution being three to four times more than could be accounted for by the fibre block that persisted after the staircase. The diminution may, however, be due to block of fibres during the staircase, only those fibres being potentiated that were activated during 


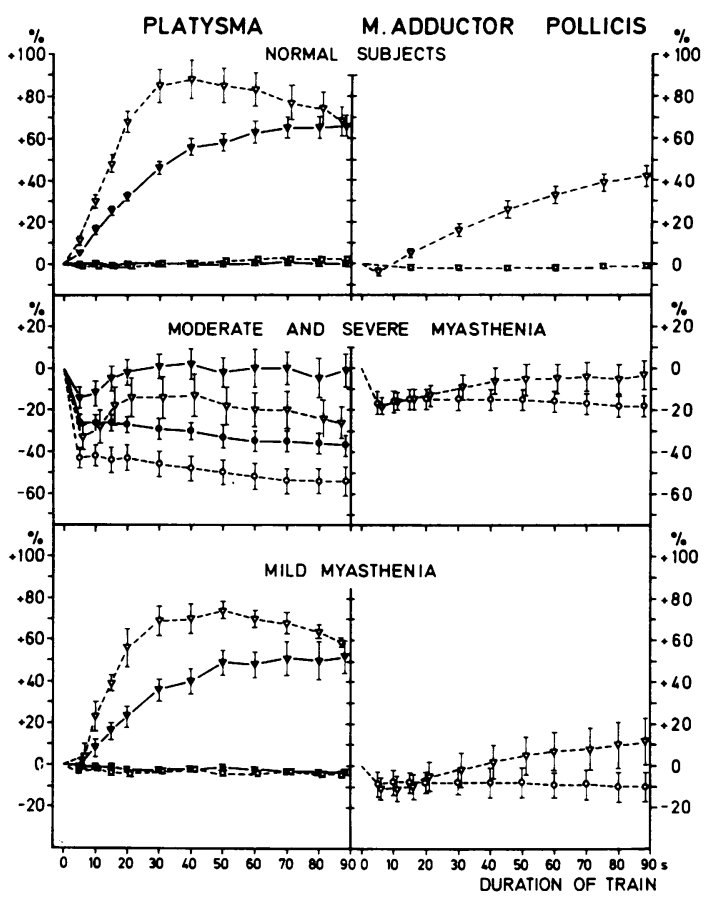

Fig. 6 Changes in electrical $(O, \bullet)$ and mechanical $(\nabla, \nabla)$ responses in per cent during the staircase (dashed line), open symbols: $2 s^{-1}$ for 90 seconds; full line, solid symbols: $1 \mathrm{~s}^{-1}$ for 90 seconds), in the platysma and in the ADP in normal subjects and in patients with myasthenia gravis. The vertical bars denote the mean error. most of the staircase. This interpretation is consistent with the greater potentiation after the $1 \mathrm{~s}^{-1}$ than after the $2 s^{-1}$ staircase, the latter frequency causing more fibres to be blocked in moderate and severe myasthenia.

The post-tetanic increase in twitch tension in myasthenia gravis is due to (1) PTF - that is, activation of previously blocked fibres, associated with an increase in the muscle action potential, and (2) to persisting PTP - that is, increased tension in the individual muscle fibre, which is lower than normal, either because of a defect in excitation-contraction coupling or because of block of fibres during tetanus that are therefore not potentiated. The initial steep slope of the decrease in twitch tension after tetanus reflects PTF and the later flatter slope reflects PTP.

The increase in twitch: tetanus ratio and in the rate of relative force development, and the decrease in tetanic tension in myasthenia gravis may be due to block of muscle fibres. This is reflected in the large decrement in the action potential early in tetanus, and does not necessarily indicate a lesion in the contractile mechanism assumed in the ADP, because the increased twitch:tetanus ratio and the decreased tetanic tension were also present in the directly stimulated ADP (Slomić et al., 1968). Thus, in the platysma, block in neuromuscular transmission can explain the low poststaircase potentiation, the low PTP, the low tetanic tension, and the increased twitch:tetanus ratio and rate of relative force development. It cannot explain the diminished staircase found when correction was made for fibre block, indicating that excitation-contraction coup-

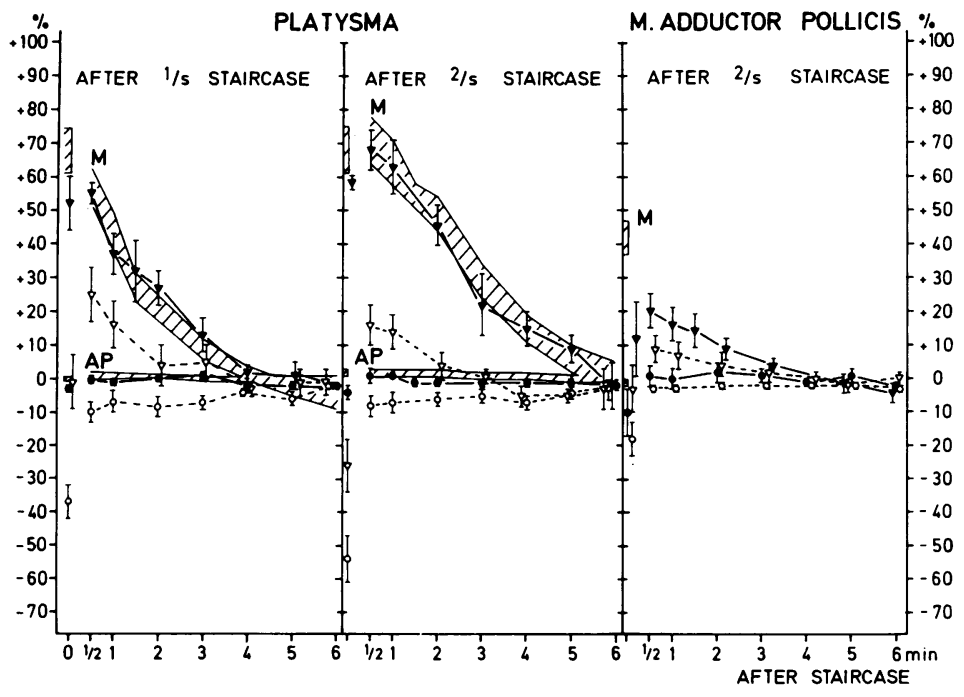

Fig. 7 Increase in action potential amplitude $(A P, \bigcirc, \bullet)$ and in twitch tension $(M, \nabla, \nabla)$ after the staircase in per cent of the amplitude before the staircase $\left(1 s^{-1}\right.$ and $2 s^{-1}$ for 90 seconds) in patients with moderate and severe (open symbols) and mild myasthenia gravis (solid symbols). The hatched area indicates findings in normal subjects \pm mean error. 
ling was involved in some cases of myasthenia gravis, at variance with the assumption of Desmedt et al. (1973).

In patients with mild myasthenia gravis there was usually no block of fibres in the rested muscle, suggested by the absent PTF in the platysma, whereas the action potential was decreased in one-third of the patients after a $50 \mathrm{~s}^{-1}$ tetanus, probably due to persisting block of fibres. In moderate and severe myasthenia gravis the persisting block was counteracted by PTF and was seen in the subsequent transient decrease within the first minute after tetanus. The persisting block was more evident in moderate and severe myasthenia gravis two seconds after 10 and $20 \mathrm{~s}^{-1}$ stimuli, because facilitation of neuromuscular transmission was less easily elicited.

In the platysma but not in the ADP the facilitation caused by a preceding tetanus was related to the size of the action potential evoked by single stimuli after application of edrophonium. With one exception the prejunctional facilitation after tetanus was greater than the postjunctional facilitation by edrophonium (Fig. 8).

\section{DIAGNOSTIC YIELD}

This study confirms earlier findings in facial muscles of patients with myasthenia gravis, that there was often more decrement in the action potential evoked by repetitive stimuli than in a distal muscle (Botelho

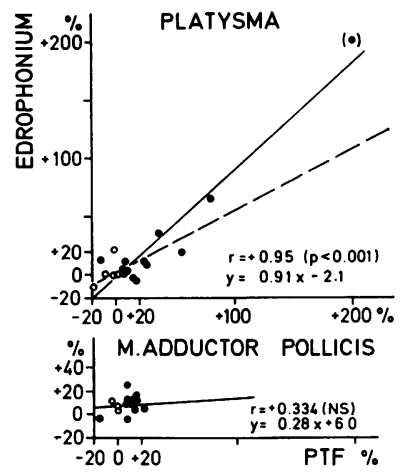

Fig. 8 Change in the amplitude of the action potential evoked by single stimuli after edrophonium chloride $(10 \mathrm{mg})$ as a function of the change after a tetanus (50 stimuli per second for 1.5 seconds) in patients with moderate or severe (solid symbols) and mild myasthenia gravis (open symbols). In the platysma the solid line represents the regression line when the point in parentheses was included (correlation coefficient, +0.95 ), the dashed line when it was omitted (correlation coefficient, $+0.73, P<0.001$, slope, +0.53$)$. In the $A D P$ the relation was not significant $(N S)$. et al., 1952; Goddé-Jolly and Marteret, 1964; Borenstein and Desmedt, 1973).

Six of my patients had abnormalities solely in the platysma. The abnormalities were more pronounced in the platysma than in the ADP in 10 patients, the same in five, and more in the ADP than in the platysma in three patients.

The largest diagnostic yield was found with $2-10 \mathrm{~s}^{-1}$ stimuli, in agreement with Johns et al. (1956), Lambert et al. (1961), and Desmedt (1966). Twenty patients had abnormalities in the platysma and 12 in the ADP at these frequencies. Abnormalities in the platysma were confirmed in most patients by prolonged stimulation, but the staircase phenomenon was abnormal in the ADP in three patients, whereas there was no decrement in brief trains at $3 \mathrm{~s}^{-1}$. Pretetanic decrement during $3 \mathrm{~s}^{-1}$ trains was borderline in the platysma in four patients and in one in the ADP whereas post-tetanic decrement was clearly abnormal. Post-tetanic block of the action potential in the platysma was the only abnormality in one patient. The one patient in complete remission showed PTF and an absent staircase in the ADP, but in the platysma it was normal. The patient had moderate myasthenia when examined bs is Slomić et al. (1968) (patient XVII).

Abnormalities in the platysma were found in 2웅응 patients, in the ADP in 18 . All 24 patients showe abnormalities in one muscle or the other.

My thanks are due to Professor F. Buchthal for his unfailing help, criticism, and inspiration, since started this work as a medical student, to Dr ZF Kamieniecka for evaluating the muscle biopsies, and to the following Departments of Neurology for referring patients under their care: Rigshospital, Copenhagen, Community Hospital, Gentofte County Hospital, Bispebjerg Hospital, Frederiksberg Hospital, and Aalborg, Community Hospital. The work was supported by grants from the Muscular Dystrophy Associations of America, Inc., and the Michaelsen Foundation, Copenhagen.

\section{References}

Ballantyne, J. P., and Hansen, S. (1974a). A new method for the estimation of the number of motor units in muscle. 1. Control subjects and patients with myasthenia gravis. Journal of Neurology, Neurosurgery, and Psychiatry, 37, 907-915.

Ballantyne, J. P., and Hansen, S. (1974b). Computer method for the analysis of evoked motor unit potentials. $\frac{D}{0}$ 1. Control subjects and patients with myasthenia gravis. Journal of Neurology, Neurosurgery, and N Psychiatry, 37, 1187-1194.

Bergman, R. A., Johns, R. J., and Afifi, A. K. (1971). N Ultrastructural alterations in muscle from patients $\underset{\mathrm{N}}{\mathrm{N}}$ 
with myasthenia gravis and Eaton-Lambert syndrome. Annals of the New York Academy of Sciences, 183, 88-122.

Bergmans, J., Roselle, N., Verheyen, G., and Schellens, L. (1972). An electrophysiological analysis of the storage of transmitter. Electromyography and Clinical Neurophysiology, 12, 443-488.

Borenstein, S., and Desmedt, J. E. (1973). New diagnostic procedures in myasthenia gravis. In New Developments in Electromyography and Clinical Neurophysiology, vol. 1, pp. 350-374. Edited by J. E. Desmedt. Karger: Basel.

Borenstein, S., and Desmedt, J. E. (1974). Temperature and weather correlates of myasthenic fatigue. Lancet 2, 63-66.

Borenstein, S., and Desmedt, J. E. (1975). Local cooling in myasthenia-improvement of neuromuscular failure. Archives of Neurology (Chic.), 32, 152-157.

Botelho, S. Y., Deaterly, C. F., and Comroe, J. H. (1952). Electromyogram from orbicularis oculi in normal persons and in patients with myasthenia gravis. Archives of Neurology and Psychiatry (Chic.), 67, 348-353.

Brody, I. A., and Engel, W. K. (1964). Denervation of muscle in myasthenia gravis. Archives of Neurology (Chic.), 11, 350-354.

Brooke, M. H., and Engel, W. K. (1969). The histographic analysis of human muscle biopsies with regard to fiber types. 3. Myotonias, myasthenia gravis, and hypokalemic periodic paralysis. Neurology (Minneap.), 19, 469-477.

Brownell, B., Oppenheimer, D. R., and Spalding, J. M. K. (1972). Neurogenic muscle atrophy in myasthenia gravis. Journal of Neurology, Neurosurgery, and Psychiatry, 35, 311-322.

Desmedt, J. E. (1966). Presynaptic mechanism in myasthenia gravis. Annals of the New York Academy of Sciences, 135, 209-246.

Desmedt, J. E. (1973). The neuromuscular disorder in myasthenia gravis. I. Electrical and mechanical response to nerve stimulation in hand muscle. In New Developments in Electromyography and Clinical Neurophysiology, vol. 1, pp. 241-304. Edited by J. E. Desmedt. Karger: Basel.

Desmedt, J. E., Emeryk, B., Hainaut, K., Reinhold, H., and Borenstein, S. (1973). Muscular dystrophy and myasthenia gravis. (Muscle contraction properties studied by the staircase phenomenon). In New Developments in Electromyography and Clinical Neurophysio$\log y$, vol. 1, pp. 380-399. Edited by J. E. Desmedt. Karger: Basel.

Engel, W. K., and McFarlin, D. E. (1966). Discussion. Annals of the New York Academy of Sciences, 135, 68-78.
Fenichel, G. M. (1966). Muscle lesions in myasthenia gravis. Annals of the New York Academy of Sciences, 135, 60-67.

Fenichel, G. M., and Shy, M. (1963). Muscle biopsy experience in myasthenia gravis. Archives of Neurology (Chic.), 9, 237-243.

Goddé-Jolly, D., and Marteret, M. H. (1964). Une technique de stimulation du muscle orbiculaire des paupières et sa réponse électromyographic dans le diagnostic de la maladie d'Erb-Goldflam. Bulletin des Sociétés d'Ophtalmologie, 64, 1017-1020.

Johns, R. J., Grob, D., and Harvey, A. M. (1956). Studies in myasthenia gravis. II. Effects of nerve stimulation in normal subjects and in patients with myasthenia gravis. Johns Hopkins Hospital Bulletin, 99, 125-135.

Krarup, C. (1977). Electrical and mechanical responses in the platysma and in the adductor pollicis muscle: in normal subjects. Journal of Neurology, Neurosurgery, and Psychiatry, 40, 234-240.

Lambert, E. H., Rooke, E. D., Eaton, L. M., and Hodgson, C. H. (1961). Myasthenic syndrome occasionally associated with bronchial neoplasm: neurophysiologic studies. In Myasthenia Gravis, pp. 362-410. Edited by R. H. Viets. Thomas: Springfield, Ill.

Oosterhuis, H., and Bethlem, J. (1973). Neurogenic muscle involvement in myasthenia gravis. A clinical and histopathological study. Journal of Neurology, Neurosurgery, and Psychiatry, 36, 244-254.

Oosterhuis, H. J. G. H., Hootsmans, W. J. M., Veenhuyzen, H. B., and Zadelhoff, I. van. (1972). The mean duration of motor unit action potentials in patients with myasthenia gravis. Electroencephalography and Clinical Neurophysiology, 32, 697-700.

Osserman, K. E., and Genkins, G. (1971). Studies in myasthenia gravis: Review of a twenty-year experience in over 1200 patients. The Mount Sinai Journal of Medicine, 38, 497-537.

Reinhold, H., Hainaut, K., and Desmedt, J. E. (1970). "Relative" staircase potentiation of the muscle twitch in the partially curarized normal human muscle. Archives Internationales de Pharmacodynamie et de Thérapie, 185, 204-207.

Simpson, J. A. (1960). Myasthenia gravis: a new hypothesis. Scottish Medical Journal, 5, 419-436.

Simpson, J. A. (1974). Myasthenia gravis and myasthenic syndromes. In Disorders of Voluntary Muscle, 3rd ed pp. 653-692. Edited by J. N. Walton. Churchill Livingstone: Edinburgh and London.

Slomić, A., Rosenfalck, A., and Buchthal, F. (1968). Electrical and mechanical responses of normal and myasthenic muscle-with particular reference to the staircase phenomenon. Brain Research, 10, 1-78. 